\title{
IUI needs fairer appraisal to improve patient and stakeholder choices
}

\author{
Gulam Bahadur ${ }^{1}$, Bryan Woodward², Megan Carr ${ }^{3}$, Santanu Acharya ${ }^{4}$, Asif Muneer ${ }^{5}$, Roy Homburg ${ }^{6}$ \\ ${ }^{1}$ Reproductive Medicine Unit, North Middlesex University Hospital, Old Admin Block, London N18 1QX, UK \\ ${ }^{2} \mathrm{X} \& Y$ Fertility, Leicester, UK \\ ${ }^{3}$ Chelsea Westminster Hospital/West Middlesex Hospital University Trust, Twickenham Road, Isleworth TW7 6AF \\ ${ }^{4}$ Ayrshire Fertility Unit, University Hospital Cross house, Kilmarnock, KA2 OBE, Scotland \\ 5University College London Hospital, 250 Euston Road. London NW1 2PG \\ ${ }^{6}$ Homerton Fertility Centre, Homerton University Hospital, London E9 6SR, UK
}

\begin{abstract}
Information supporting IVF at the expense of intrauterine insemination (IUI) has become commonplace, but it lacks critical analyses. Data from poorly practiced IUI, without an equivalent comparison to IVF, has been generalised to recommend a total abandonment of IUI in favour of IVF treatment. Our intention with this paper is to reappraise and balance arguments so that patients and stakeholders can have an unbiased informed choice. We provide information that reveals IUI to predominate over IVF in terms of integrated success, risks and cost to deliver one live birth whilst obviating the maternal and neonatal costs. Exceptional cost savings are demonstrated for IUI over IVF for fee-paying agencies and patients with lowered risks of maternal and neonatal care along with other risks including OHSS, fetal reduction and termination of pregnancies. This analysis supports the view that patients and stakeholders can choose IUI instead of IVF in most instances, except with bilateral tubal blockage and severe male factor infertility. It is apparent that fertility clinics need to re-evaluate and reconsider this field, and IUI can be of benefit to both subfertile patients and the stakeholders.
\end{abstract}

Keywords: IVF, IUI, cost efficiency, public health, stakeholder

\section{BACKGROUND}

Questions on how RCTs and the potential selection bias compared to big data, are particularly relevant for ART, where there is interest. Crucially, the UK's National Institute of Health and Care Excellence (NICE) recommended that IUI treatment should be replaced by 3 cycles of IVF treatment, following appraisal of IUI studies with very low doses of clomiphene citrate (CC) $(25 \mathrm{mg})$ and without comparative data (Bahadur et al., 2017; Wordsworth et al., 2011). The FASST (Fast Track and Standard Treatment) trial had several weaknesses due to the in-built biases omitting IUI/hMG cycles and suggesting the premature use of IVF (Reindollar et al., 2010). That IUI/hMG serves a potential 'threat' to IVF is encapsulated in a further meta-analysis that focussed solely on high risk IUI/hMG studies, and then concluded that IUI/hMG should not be practiced whatsoever (Hansen, 2020; Zolton et al., 2020). In our opinion, almost all of the cases in this meta-analysis would have warranted cancellation, and the paper (Hansen, 2020; Zolton et al., 2020) is biased in favour of IVF treatment. Furthermore, none of the limitations was made clear to stakeholders and this requires analyses that are more critical. Financial analyses on cost effectiveness have so far been conducted crudely and seem overly concerned to portray IUI treatment as cost-inefficient. However, such analyses select poorly practised IUI cases, which are then utilized by Clinical Commissioning Groups (CCG) as evidence for NICE (2014). The most recent Cochrane analyses acknowledges that IUI in a stimulated cycle may result in a higher cumulative live birth rate compared to natural cycle IUI (Ayeleke et al., 2020).

With the proliferation of meta-analyses in the medical literature, these have come under considerable criticism for the level of arbitrary and selection biases (Page et al., 2014), raising questions regarding the validity of the data. Of particular interest is the systematic review and meta-analysis (Zolton et al., 2020) comparing live births and multiple gestations in couples with unexplained infertility undergoing IUI, following ovarian stimulation (OS-IUI) with oral medications versus gonadotropins. This study concludes that gonadotropin-stimulated IUI cycles in unexplained infertility could not be supported, and contrasts the largest comparative and integrated analyses between IVF and IUI (Bahadur et al., 2020). We express caution regarding the conclusions, which appear to preclude less invasive fertility treatments than IVF (Bahadur et al., 2020).

Interestingly, the eight studies chosen after rigorous selection could all be considered as 'high risk', since they include a decision to proceed to treatment, thus exposing mothers and babies to potential harm (Zolton et al., 2020). In two studies, no cancellation policy was presented, whilst the remaining studies permitted insemination with 3-7 follicles. Most practitioners would exercise caution with such high follicle numbers. Furthermore, non-cancellation might even be considered to amount to poor practice, unless there were a maximum of 3 follicles and where case-bycase assessment was made. There is no clear information as to how many mature follicles were present, which resulted in multiple births. The cases considered were not purely unexplained, and up to $50 \%$ of the cases appear to be mixed male factor; therefore, negating the authors' claim that the strength of the study is in the number of 2,989 unexplained infertile couples (Zolton et al., 2020).

Whilst elective single embryo transfer (eSET) has been shown to be an effective strategy in reducing the number of multiple births after IVF cycles, it is inappropriate to compare this to high risk IUI practices if no comparative multiple birth data is presented in well managed IUI/hMG cycles. The authors allude to a cancellation of around $6.9 \%$ in their high risk IUI category, leaving the readers to imagine such a cancellation level would apply to all IUI gonadotropin well-managed cycles and that high multiple birth rates remains unavoidable.

More significant is the fact that the success rate for gonadotrophin-stimulated IUI cycles was $31.8 \%$, which was much higher than the most recent IVF mean UK national 
figures from Human Fertilisation \& Embryology Authority (HFEA), where even the best rates in women under the age of 35 years is $29 \%$ for IVF and $18 \%$ for OS-IUI (HFEA, 2020a; b). This point needs to be positively harnessed and worked in ways to minimise multiple births. IVF remains the single most important factor for multiple births and comparisons with high-risk IUI cycles serves an unnecessary distraction (Bahadur et al., 2020). Numerous well-constructed evidence-based studies support IUI (Bensdorp et al., 2015; Nandi et al., 2017; Tjon-KonFat et al., 2017). The recent Cochrane review acknowledges IUI in a stimulated cycle may result in a higher cumulative live birth rate when compared to treatment with IUI in a natural cycle review (Ayeleke et al., 2020).

The USA does not classify IUI as an ART procedure. However, if it were included, this could potentially highlight to patients and funding agencies the option of a low risk, cost-effective treatment option. The largest integrated and comparative study undertaken on this topic places IUI in the context of IVF without the biases seen in numerous papers (Bahadur et al., 2020). This concludes that patients and stakeholders would well be advised to undergo IUI before IVF in most cases. The baseline IUI: IVF success rates to deliver a live birth (LB) was 2.35:1, which was much narrower than the RCT reported of 3:1. A small improvement in IUI LBR from $12.1 \%$ to $15.6 \%$ LBR narrows this difference to $1.73: 1$. The paper informs patients and stakeholders that 3.7 IVF cycles or 8.69 IUI cycles at $12.1 \%$ LBR or 6.4 cycle for a $15.6 \%$ LBR IUI are required to achieve a $100 \%$ theoretical LB. Despite creative ways of presenting IVF success rates, $70 \%$ of the women will never achieve an IVF baby. The multiple births for IVF were significantly greater than for IUI, despite the increasing eSET practice. IVF pregnancies were also associated with a $0.2 \%$ fetal reduction as a way to lessen multiple births. The paper reveals other risks for IVF, such as terminations for medical and a small number due to personal and social reasons. The knock-on effect for maternal and neonatal cost per year to the UK from IVF babies was $£ 115$ million, a cost burden not picked up by IVF clinics. The unique algorithms developed reveal that IUI clinics could deliver a cost-effective benefit per LB of $£ 42558$, while extending this benefit to $£ 76257$ for $15.6 \%$ LB IUI against IVF $27.3 \%$ LB. IVF clinics providing 'add-on' techniques simply increase the cost, thereby eroding any cost benefit IVF can deliver per LB, while increasing the cost efficiency of IUI LB. On an economic and scientific basis, it is worthwhile investing in IUI LB improvement, when considering non-evidenced based addons with no proven worth. By its own financial guidelines, NICE is compelled to inform UK CCGs to fund IUI before IVF, given the cost efficiencies deliverable from IUI procedures (Bahadur et al., 2020; NICE, 2014). For the first time this unfettered unique analysis provides fee-paying stakeholders, patients and governments crafting policies detailed information to make informed choices away from IVF clinics.

To conclude, the politics of influencing crucial bodies to construct treatment policies and funding criteria require interest groups to provide evidence through peer reviewed papers. Such bodies dismiss large grey data unpublished in peer reviewed journals. It has been all too easy to exploit these loopholes for those motivated to generate evidence on a variety of levels and in favour of more profitable IVF treatments despite weak to very weak evidence. It is therefore imperative to gain a balanced view of the field of ART dealing with highly sensitive and vulnerable patients. For the first time, a sizable and a bird's eye view analyses make a compelling case for IUI treatment before embarking on IVF treatment, based on outcomes, risks and cost effectiveness.
We recommend that fertility treatment policies are constructed to use the new information away from IVF clinic pressures.

\section{CONFLICT OF INTEREST}

The author has no conflict of interest to declare.

\section{Corresponding author:}

Gulam Bahadur

Reproductive Medicine Unit

North Middlesex University Hospital Old Admin Block

London, UK.

E-mail: bahadur.g@gmail.com

\section{REFERENCES}

Ayeleke RO, Asseler JD, Cohlen BJ, Veltman-Verhulst SM. Intra-uterine insemination for unexplained subfertility. Cochrane Database Syst Rev. 2020;3:CD001838. PMID: 32124980. DOI: 10.1002/14651858.CD001838.pub6

Bahadur G, Woodward B, Homburg R, Al-Habib A, Muneer A. Pitfalls of NICE recommendations on fertility treatment. BMJ. 2017;356:j751. PMID: 28193611. DOI: 10.1136/bmj.j751

Bahadur G, Homburg R, Bosmans JE, Huirne JAF, Hinstridge $P$, Jayaprakasan K, Racich P, Alam R, Karapanos I, Illahibuccus A, Al-Habib A, Jauniaux E. Observational retrospective study of UK national success, risks and costs for 319,105 IVF/ICSI and 30,669 IUI treatment cycles. BMJ Open. 2020;10:e034566. PMID: 32184314. DOI: 10.1136/bmjopen-2019-034566

Bensdorp AJ, Tjon-Kon-Fat RI, Bossuyt PM, Koks CA, Oosterhuis GJ, Hoek A, Hompes PG, Broekmans FJ, Verhoeve $H R$, de Bruin JP, van Golde R, Repping S, Cohlen BJ, Lambers MD, van Bommel PF, Slappendel E, Perquin D, Smeenk JM, Pelinck MJ, Gianotten J, et al. Prevention of multiple pregnancies in couples with unexplained or mild male subfertility: randomised controlled trial of in vitro fertilisation with single embryo transfer or in vitro fertilisation in modified natural cycle compared with intrauterine insemination with controlled ovarian hyperstimulation. BMJ. 2015;350:g7771. PMID: 25576320. DOI: 10.1136/bmj.g7771

Hansen KR. Gonadotropins with intrauterine insemination for unexplained infertility-time to stop? Fertil Steril. 2020;113:3334. PMID: 32106982 DOI: $10.1016 / j$.fertnstert.2019.10.022

HFEA - Human Fertilisation \& Embryology Authority. In vitro fertilisation (IVF). 2020a. Available at: https://www. hfea.gov.uk/treatments/explore-all-treatments/in-vitro-fertilisation-ivf/

HFEA - Human Fertilisation \& Embryology Authority. Intrauterine insemination (IUI). 2020b. Available at: https:// www.hfea.gov.uk/treatments/explore-all-treatments/intrauterine-insemination-iui/

Nandi A, Bhide P, Hooper R, Gudi A, Shah A, Khan K, Homburg $R$. Intrauterine insemination with gonadotropin stimulation or in vitro fertilization for the treatment of unexplained subfertility: a randomized controlled trial. Fertil Steril. 2017;107:1329-35.e2. PMID: 28501361 DOI: 10.1016/j.fertnstert.2017.03.028

NICE - National Institute of Health and Care Excellence. Developing NICE guidelines: the manual Process and methods; 2014. Available at: nice.org.uk/process/ pmg20 
Page MJ, McKenzie JE, Kirkham J, Dwan K, Kramer S, Green S, Forbes A. Bias due to selective inclusion and reporting of outcomes and analyses in systematic reviews of randomised trials of healthcare interventions. Cochrane Database Syst Rev. 2014;10:MR000035. PMID: 25271098 DOI: $10.1002 / 14651858 . M R 000035 . p u b 2$

Reindollar RH, Regan MM, Neumann PJ, Levine BS, Thornton $\mathrm{KL}$, Alper MM, Goldman MB. A randomized clinical trial to evaluate optimal treatment for unexplained infertility: the fast track and standard treatment (FASTT) trial. Fertil Steril . 2010;94:888-99. PMID: 19531445 DOI: 10.1016/j. fertnstert.2009.04.022

Tjon-Kon-Fat RI, Tajik P, Zafarmand MH, Bensdorp AJ, Bossuyt PMM, Oosterhuis GJE, van Golde R, Repping $S$, Lambers MDA, Slappendel E, Perquin D, Pelinck MJ, Gianotten J, Maas JWM, Eijkemans MJC, van der Veen F, Mol $B W$, van Wely $M$; INeS study group. IVF or IUI as first-line treatment in unexplained subfertility: the conundrum of treatment selection markers. Hum Reprod. 2017;32:102832. PMID: 28333222 DOI: 10.1093/humrep/dex037
Wordsworth S, Buchanan J, Mollison J, Harrild K, Robertson $L$, Tay C, Harrold A, McQueen D, Lyall $H$, Johnston L, Burrage J, Grossett S, Walton H, Lynch J, Johnstone A, Kini S, Raja A, Templeton A, Bhattacharya S. Clomifene citrate and intrauterine insemination as first-line treatments for unexplained infertility: are they cost-effective? Hum Reprod. 2011;26:36975. PMID: 21127355 DOI: 10.1093/humrep/deq315

Zolton JR, Lindner PG, Terry N, DeCherney AH, Hill MJ. Gonadotropins versus oral ovarian stimulation agents for unexplained infertility: a systematic review and meta-analysis. Fertil Steril. 2020;113:417-25.e1. PMID: 31973903 DOI: $10.1016 /$ j.fertnstert.2019.09.042 